\title{
KAJIAN KESIAPAN UMKM BATIK SURAKARTA TERHADAP DIMENSI EKONOMI CERDAS SEBAGAI BAGIAN DARI PENERAPAN KONSEP SMART CITY
}

\author{
Study of SMEs Surakarta Batik Readiness on Smart Economy \\ Dimension as Part of Smart City Concept Implementation
}

\section{Godlive H I Sitorus ${ }^{1}$, Wido Prananing Tyas ${ }^{2}$}

Diterima: 28 Maret 2018 Disetujui: 17 Agustus 2018

\begin{abstract}
Abstrak:: Kota Surakarta (Solo) saat ini sedang dalam tahapan proses untuk mewujudkan konsep Solo Smart City. Sektor UMKM Batik Surakarta menjadi salah satu fokus pemerintah untuk dapat didorong agar mampu menerapkan prinsip-prinsip ekonomi cerdas dalam kegiatannya. Penelitian ini bertujuan untuk melihat bagaimana tingkat kesiapan UMKM Batik Surakarta agar dapat dilihat seberapa kuat peran UMKM Batik Surakarta dalam mendorong terwujudnya penerapan dimensi ekonomi cerdas. Penilaian kesiapan dilakukan dengan menganalisis kondisi lima indikator ekonomi cerdas, yaitu: innovative spirit, kolaborasi dan partisipasi, entrepreneurship, produktivitas, dan daya saing. Level kesiapan yang didesain dalam penelitian ini dibagi dalam tiga kategori, yaitu siap, siap bersyarat, dan belum siap. Metode penelitian yang digunakan pada penelitian ini adalah metode kuantitatif dengan penggunaan data campuran kualitatif dan kuantitatif. Teknik analisis yang digunakan adalah skoring. Hasil dari penelitian ini menyimpulkan bahwa tingkat kesiapan UMKM Batik Surakarta berada pada level kesiapan siap bersyarat, artinya UMKM Batik Surakarta pada dasarnya dapat dikatakan siap untuk mewujudkan dimensi ekonomi cerdas, namun ada beberapa aspek yang perlu menjadi perhatian untuk dikembangkan agar dapat benar-benar mendorong terwujudnya dimensi ekonomi cerdas, yaitu (1) aspek pengambilan keputusan pada indikator innovative spirit, (2) aspek kolaborasi pada indikator innovative spirit, dan (3) sistem manajemen administrasi usaha pada indikator produktivitas.
\end{abstract}

\section{Kata kunci: Smart city, ekonomi cerdas, UMKM Batik Surakarta}

Abstract: The city of Surakarta (Solo) is currently in the process stage to realize the concept of Solo Smart City. SMEs Surakarta Batik sector became one of the focus of government to be encouraged to be able to apply the principles of smart economy in its activities. This study aims to see how the level of readiness of SMEs Surakarta Batik in order to see how strong the role of SMEs Surakarta Batik in encouraging the implementation of smart economic dimensions. Assessment of readiness is done by analyzing the condition of five smart economic indicators, namely: innovative spirit, collaboration and participation, entrepreneurship, productivity, and competitiveness. The readiness levels designed in this study are divided into three categories: ready, ready on condition, and not yet ready. The research method used in this research is quantitative method with the use of mixed qualitative and quantitative data. Analytical technique used is scoring. The result of this research concludes that the level of readiness of SMEs Surakarta Batik is at the level of ready on condition,

\footnotetext{
${ }^{1}$ Departemen Perencanaan Wilayah dan Kota, Universitas Diponegoro
} 
meaning that SMEs Surakarta Batik basically can be said ready to realize the smart economic dimension, but there are some aspects that need attention to be developed in order to really pushing the realization (1) aspects of decision making on innovative spirit indicators, (2) aspects of collaboration on innovative spirit indicators, and (3) business administration management systems on productivity indicators.

Keywords: Smart city, smart economy, SMEs Surakarta Batik

\section{PENDAHULUAN}

Berdasarkan buku statistik daerah Kota Surakarta tahun 2016, Kota Surakarta merupakan kota terpadat di Jawa Tengah dengan jumlah penduduk sebesar 586.036 dan kepadatan penduduk sebesar 11,630 jiwa/km2, selain itu juga merupakan salah satu kota yang memiliki sisi keunikan dan keunggulan ekonomi melalui komoditas tekstilnya, yaitu produk batik atau yang dikenal dengan nama Batik Solo (Surakarta). Pertumbuhan usaha batik memang cukup tinggi pada tahun-tahun awal paska diakuinya batik sebagai warisan dunia dari Indonesia oleh UNESCO, bahkan pertumbuhannya dalam beberapa tahun sempat mencapai 35-50\%. Namun dalam beberapa tahun terakhir jumlahnya justru semakin menunjukkan tingkat penurunan, ada beberapa faktor yang menyebabkan kondisi tersebut, baik yang berasal dari faktor internal maupun faktor eksternal. Oleh karenanya pemerintah mengupayakan sektor UMKM Batik Surakarta agar menjadi prioritas pengembangan sektoral yang disusun sebagai upaya mewujudkan Solo Smart City. Sektor UMKM Batik Surakarta didorong agar mampu menerapkan sistem ataupun pola kegiatan usaha baru sesuai dengan prinsip-prinsip smart city dari dimensi ekonomi cerdas.

Apabila melihat dari karakteristiknya, sebagian besar pelaku UMKM Batik di Surakarta seperti yang terdapat di salah satu sentra batik Surakarta, yaitu Kampung Batik Laweyan, tenaga kerja yang bekerja di sektor UMKM Batik didominasi oleh pekerja kalangan tua yang seringkali cenderung sulit untuk memahami dan menerima pengetahuanpengetahuan baru untuk pengembangan UMKM Batik itu sendiri. Meskipun demikian, pelaku UMKM yang merupakan kalangan muda juga jumlahnya dapat dikatakan tidak sedikit. Berdasarkan hasil penelitian-penelitian terdahulu mengenai studi yang dilakukan terhadap UMKM Batik Surakarta yang terpusat di Kampung Batik Laweyan dan Kampung Batik Kauman, menyatakan bahwa penerapan-penerapan ICT (Information Communication Technologies) dalam kegiatan usaha masih bersikap konservatif dan menyebabkan penetrasinya tidak begitu cepat. Hal inilah yang menyebabkan munculnya dugaan bahwa sektor UMKM Kota Surakarta saat ini belum berada pada level smart. Berdasarkan pernyataan Supangkat (2015), kondisi UMKM yang mencapai level smart adalah UMKM yang mampu menciptakan efektivitas dan efisiensi usaha melalui dukungan layanan yang saling terintegrasi dan masyarakatnya selaku pelaku ekonomi memiliki kemampuan dan akses yang baik terhadap TIK. Maka dari itu, untuk mengukur level kesiapan tersebut, diperlukan suatu kegiatan penilaian serta penelitian mengenai seberapa jauh penerapan prinsip ekonomi cerdas dapat dilakukan oleh UMKM Batik Surakarta, sehingga akan dapat disimpulkan bagaimana tingkat kesiapan UMKM Batik Surakarta untuk mendorong terwujudnya penerapan sistem smart city dari dimensi ekonomi cerdas. Perwujudan sistem perekonomian perkotaan yang smart merupakan tantangan-tantangan yang harus dihadapi kota-kota di Indonesia mengingat tingkat persaingan yang semakin kompetitif di era globalisasi saat ini dan sebagaimana diketahui bahwa Negara Indonesia sejak tahun 2016 merupakan salah satu negara anggota yang masuk dalam komunitas masyarakat ekonomi ASEAN (MEA), sehingga bila UMKM Batik Surakarta ke depannya tidak mampu beradaptasi dengan perdagangan bebas di masa kini dan yang akan datang, maka dikhawatirkan akan 
menyebabkan pelemahan atau penurunan performa pada sektor industri dan perdagangan bagi Kota Surakarta.

Tujuan dari penelitian ini adalah untuk menganalisis dan mengkaji tingkat kesiapan UMKM Batik Surakarta dalam mencapai sistem dimensi ekonomi cerdas sebagai bagian dari smart city dengan pertanyaan penelitian yang menjadi fokusnya adalah "Bagaimana tingkat kesiapan UMKM Batik Surakarta dalam menghadapi sistem smart city Kota Surakarta berdasarkan capaian indikator-indikator dari dimensi ekonomi cerdas?". Pada hasil kesimpulan nantinya tujuan dan pertanyaan penelitian tersebut akan dijawab dan dijabarkan berdasarkan hasil temuan-temuan di lapangan yang telah dianalisis secara sistematis, metodis dan juga koheren sehingga kesimpulan atau jawaban dari pertanyaan penelitian dapat terjawab secara objektif. Perlu diketahui bahwa pengembangan kota yang dilakukan dengan pendekatan smart city adalah kegiatan yang sifatnya sistematis dan bertahap. Terdapat beberapa mekanisme yang perlu dilakukan untuk dapat mewujudkan konsep smart city, seperti mengkaji identitas smart city apa yang akan dijadikan sebagai ciri khas kota tersebut yang didasari dari potensi maupun permasalahan, menilai tingkat kesiapan sektorsektor yang akan dikembangkan dengan pendekatan smart city, serta membuat roadmap pengembangan smart city yang kemudian akan diturunkan ke dalam bentuk program dan kebijakan. Adapun posisi penelitian ini berada pada level menilai tingkat kesiapan sektor perkotaan yang akan akan dikembangkan dengan pendekatan dimensi ekonomi cerdas yang merupakan bagian dari konsep smart city. Subjek penelitian yang diangkat adalah sektor UMKM Batik Surakarta. Penilaian tingkat kesiapan dimensi ekonomi cerdas pada UMKM Batik Surakarta didasari dari 5 (lima) indikator yang didapatkan dari hasil sintesis literatur terkait. Setelah itu dari masing-masing indikator diturunkan ke dalam beberapa aspek dan variabel penelitian untuk selanjutnya dilakukan analisis perhitungan skoring dan statistik deskriptif.

\section{Pengertian dan Konsep Dimensi Ekonomi Cerdas dalam Kota Cerdas}

Konsep Kota Cerdas adalah suatu konsep yang lahir dari fenomena kota-kota di dunia yang perkembangannya semakin cepat yang diakibatkan oleh beberapa faktor, salah satunya dan yang paling besar pengaruhnya adalah proses pertumbuhan penduduk yang begitu tinggi. Akibat tingginya pertumbuhan penduduk di kota, maka kota juga dituntut untuk mampu menyediakan berbagai kebutuhan dan fasilitas-fasilitas untuk menunjang aktivitas kehidupan kota, dan perlahan aktivitas pertambahan jumlah penduduk tersebut akan memberikan efek jenuh dan over capacity bagi kota tersebut, implikasinya kemudian dapat terjadi pada daerah-daerah di sekitarnya yang mengalami aktivitas "pengkotaan" atau disebut juga sebagai urbanisasi. Fenomena urbanisasi ini tentunya akan memberikan berbagai dampak baik positif dan negatif pada beberapa sektor perkotaan yang meliputi aspek spasial dan aspek non-spasial (sosial-ekonomi-lingkungan). Berdasarkan penjelasan yang diuraikan diatas, konsep kota cerdas digagas sebagai respon konseptual dan praktis atas permasalahan kota yang semakin kompleks akibat fenomena urbanisasi. Konsep kota cerdas diarahkan agar mampu mewujudkan tujuan kota berkelanjutan melalui mekanisme yang sistematis dalam perspektif jangka panjang. Defenisi lainnya mengenai konsep kota cerdas yaitu sebuah paradigma baru pembangunan kota yang berfokus pada penciptaan sistem tata kelola perkotaan yang lebih efektif dan efisien dengan menitikberatkan pada bidang ICT (Information Communication Technologies) dalam pengaplikasiannya, sehingga konsep ini dinilai akan mampu menghadapi tantangan pembangunan yang berkelanjutan (Joshi, Saxena, Godbole, \& Shreya, 2016). Menurut Supangkat (2015) dalam pengembangan konsep kota cerdas di Indonesia, terdapat 3 (tiga) faktor utama yang menjadi indeks penerapan kota cerdas, diantaranya adalah faktor ekonomi, sosial, dan lingkungan. 
1. Faktor Ekonomi Cerdas dapat dilihat dari bagaimana kota tersebut mampu ditopang oleh perekonomian yang baik dengan memaksimalkan sumberdaya dan potensi kota tersebut, termasuk didukung dengan pengaplikasian teknologi, informasi dan komunikasi, serta tata kelola sumberdaya manusia yang baik.

2. Faktor Sosial dapat dilihat dari kondisi masyarakat kota yang memiliki keamanan, kemudahan, dan kenyamanan dalam melakukan interaksi sosial antar masyarakat dan pemerintah.

3. Faktor Lingkungan dapat dilihat dari kondisi masyarakat yang memiliki tempat tinggal layak huni, sehat, hemat dalam penggunaan energi yang didukung juga oleh layanan ICT dan peranan masyarakat yang baik.

Ekonomi merupakan salah satu faktor yang sangat penting yang dapat mempengaruhi seluruh kegiatan yang ada di dalam kota. Ekonomi kota terbentuk melalui berbagai aktivitas seperti perdagangan, ekosistem inovasi dan wirausaha, tingkat kompetisi, pajak, keuangan dan lainnya. Pada dimensi ekonomi cerdas dalam smart city tidak hanya menjelaskan dan terfokus pada isu-isu pendapatan, kesehatan, pendidikan, atau hal-hal yang berhubungan dengan kesejahteraan dan kebutuhan dasar saja. Namun dalam hal ini menambahkan beberapa variabel-variabel baru dari model pembangunan ekonomi seperti peningkatan kualitas hidup dan standar hidup masyarakat. Konsep ekonomi cerdas menggabungkan fitur-fitur ekonomi baru dalam penerapannya seperti produktivitas ekonomi yang tinggi, persaingan global, kemajuan dan kesejahteraan ekonomi, inovasi, dan ekonomi digital (Apostol, Bălăceanu, \& Constantinescu, n.d.).

\section{METODE}

Jumlah sampel penelitian yang digunakan pada penelitian ini adalah 55, adapun yang termasuk dalam kriteria penentuan responden tersebut yaitu pelaku usaha batik yang ada di Kampung Batik Laweyan Surakarta dan Kampung Batik Laweyan. Metode penelitian yang digunakan dalam penelitian ini adalah kuantitatif. Data yang digunakan dalam penelitian ini adalah campuran, yaitu data kualitatif dan data kuantitatif. Data-data kualitatif yang digunakan didapatkan melalui kegiatan indepth interview. Kedua jenis data yang digunakan bertujuan untuk saling memperkuat dan melengkapi, selain itu juga sebagai bentuk konfirmasi dan klarifikasi dari analisis yang dilakukan. Bila dilihat dari tujuannya, jenis penelitian ini bersifat deskriptif dengan menjelaskan dan menguraikan kondisi serta karakteristik mengenai hubungan antar komponen yang berperan dalam pengembangan UMKM Batik di Kampung Batik Laweyan dan Kampung Batik Kauman yang kemudian akan dihasilkan temuan. Pendekatan penelitian pada penelitian adalah deduktif atau biasa disebut umum-khusus, yaitu peneliti menguji pertanyaan penelitian yang diturunkan dari teori. Teori terlebih dahulu dijelaskan secara eksplisit dan membandingkannya dengan kondisi di lapangan sehingga dapat dirumuskan suatu hipotesis. Tidak ada kecenderungan metode dalam pendekatan penelitian ini. Hal ini berarti metode kuantitatif-kualitatif bebas digunakan sesuai kebutuhan analisis penelitian.

Teknik analisis yang dilakukan untuk mengukur tingkat kesiapan UMKM Batik Surakarta adalah teknik analisis skoring. Menurut Sugiono (2014), teknik analisis skoring adalah teknik analisis dengan menggunakan skor pada setiap data penelitian. Setiap pilihan jawaban memiliki tingkatan yang kemudian dikumulatifkan sehingga menghasilkan suatu kesimpulan dari permasalahan yang dicari. Teknik analisis skoring dianggap relevan digunakan pada penelitian ini dikarenakan dapat mengukur seberapa jauh penerapan ekonomi cerdas telah dicapai atau diterapkan oleh para pelaku usaha, hal ini dapat diketahui melalui setiap jawaban yang dipilih oleh responden. Untuk melihat level kesiapan UMKM Batik Surakarta dengan skor-skor yang didapatkan, maka akan dilakukan pembagian kelas dengan rumus statistik interval, yaitu: 


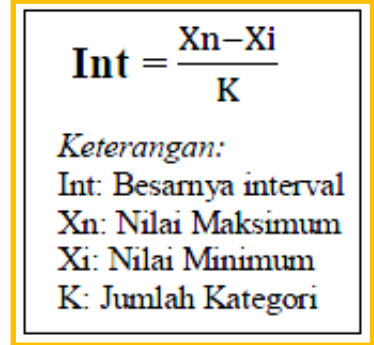

Sudjana (2008:79)
Nilai Minimum : (Jumlah variabel) $\mathrm{x}$ (jumlah responden) $\mathrm{x}$ (skor minimum) Nilai Maksimum : (Jumlah variabel) x (jumlah responden) x (skor maksimum) Nilai Interval : (Nilai maksimum - nilai minimum) / (jumlah kelas interval)

Desain kuesioner penelitian ini dibuat dengan beberapa tipe pertanyaan penelitian yang memiliki variasi jumlah pilihan jawaban, beberapa pertanyaan terdiri dari dua pilihan jawaban, tiga pilihan jawaban, dan empat pilihan jawaban. Agar data-data dapat terdistribusi normal dan dapat digunakan pada rumus diatas, maka peneliti melakukan transformasi nilai skoring dengan range antara 1 (satu) sampai dengan 12 (dua belas) karena bilangan 12 merupakan bilangan yang dapat dibagi dua, dibagi tiga, dan dibagi empat sesuai dengan variasi jumlah pilihan jawaban yang terdapat dalam kuesioner. Tabel I.3 berikut menyajikan tabel bobot untuk masing-masing pertanyaan berdasarkan jumlah pilihan jawaban.

Tabel 1. Penentuan Skor Berdasarkan Jumlah Pilihan Jawaban

\begin{tabular}{lcccc}
\hline & $\begin{array}{c}\text { Skor } \\
\text { Jawaban (a) }\end{array}$ & $\begin{array}{c}\text { Skor } \\
\text { Jawaban (b) }\end{array}$ & $\begin{array}{c}\text { Skor } \\
\text { Jawaban (c) }\end{array}$ & $\begin{array}{c}\text { Skor } \\
\text { Jawaban (d) }\end{array}$ \\
\hline Pertanyaan 2 Pilihan & 1 & 12 & - & - \\
Pertanyaan 3 Pilihan & 1 & 6 & 12 & - \\
Pertanyaan 4 Pilihan & 1 & 4 & 8 & 12 \\
\hline
\end{tabular}

Sumber: Analisis Penulis, 2017

\section{HASIL DAN PEMBAHASAN}

\section{Indikator Innovative Spirit}

Indikator innovative spirit diturunkan dari beberapa aspek penilaian, kemudian masing-masing aspek dieksplorasi dengan variabel-variabel kinerja untuk agar setiap aspek dapat dijelaskan bagaimana karakteristik performanya. Adapun aspek-aspek pada indikator innovative spirit antara lain, technology awareness, sistem pengambilan keputusan, sumberdaya manusia/ tenaga kerja, keunggulan relatif, kerja sama/ kolaborasi, dan complexity/ kedinamisan produk.

Berdasarkan hasil kegiatan penelitian di lapangan dengan menggunakan 55 sampel UMKM Batik Surakarta, total nilai skoring untuk indikator innovative spirit adalah 7.869 dan memiliki level kesiapan siap bersyarat karena nilai skoringnya berada pada range interval 5.903-10.541. Siap bersyarat artinya bahwa indikator innovative spirit pada dasarnya telah siap untuk mendukung sistem ekonomi cerdas namun masih diperlukan beberapa syarat perbaikan maupun pengadaan untuk benar-benar dapat mendukung terwujudnya dimensi ekonomi cerdas. 
Tabel 2. Skor dan Tingkat Kesiapan Aspek Indikator Innovative Spirit

\begin{tabular}{|c|c|c|c|}
\hline ASPEK & SKOR & KATEGORI & KONDISI \\
\hline Technology Awareness & 2.081 & Sangat kuat & $\begin{array}{l}\text { 88\% UMKM Batik Surakarta telah beradaptasi } \\
\text { dengan teknologi, baik dalam kegiatan produksi, } \\
\text { distribusi, pemasaran, dan pengolahan limbah. }\end{array}$ \\
\hline Sistem Pengambilan Keputusan & 483 & Lemah & $\begin{array}{l}57 \% \text { UMKM Batik Surakarta masih pasif } \\
\text { dalam hal perencanaan, evaluasi dan perlibatan } \\
\text { pekerjanya dalam pengambilan keputusan untuk } \\
\text { menciptakan inovasi usaha. }\end{array}$ \\
\hline Sumberdaya Manusia & 1.536 & Kuat & $\begin{array}{l}\quad 58 \% \text { UMKM Batik Surakarta memiliki } \\
\text { tenaga kerja yang berlatar belakang pendidikan } \\
\text { lulusan SMA/PT dan } 76 \% \text { dari tenaga kerja UMKM } \\
\text { Batik Surakarta memiliki keahlian-keahlian lain } \\
\text { yang didapatkan secara otodidak maupun melalui } \\
\text { pelatihan dan kursus. }\end{array}$ \\
\hline Keunggulan Relatif & 1.867 & Kuat & $\begin{array}{l}\text { Dari segi desain, UMKM Batik Surakarta } \\
\text { telah memiliki diferensiasi baik dalam variasi jenis } \\
\text { produk, motif, serta harga. } 56 \% \text { UMKM Batik } \\
\text { Surakarta juga mengakui telah memiliki standarisasi } \\
\text { untuk produknya }\end{array}$ \\
\hline Kerja sama/ Kolaborasi & 623 & Lemah & $\begin{array}{l}\quad 78 \% \text { UMKM Batik Surakarta belum } \\
\text { melakukan kegiatan kerjasama dan kolaborasi yang } \\
\text { bersifat sustainable antar unit internal maupun } \\
\text { eksternal sebagai upaya untuk menciptakan inovasi } \\
\text { dalam kegiatan usaha. }\end{array}$ \\
\hline Kedinamisan produk & 1.279 & Kuat & $\begin{array}{l}\text { UMKM Batik Surakarta memiliki } \\
\text { karakteristik pemikiran terbuka yang diaplikasikan } \\
\text { dalam desain, motif, dan variasi produk yang } \\
\text { beragam. Orientasi dalam menentukan desain } \\
\text { produk telah cenderung kepada kreasi dan inovasi } \\
\text { sendiri ataupun pesanan dari konsumen. }\end{array}$ \\
\hline TOTAL & 7.869 & \multicolumn{2}{|c|}{ SIAP BERSYARAT } \\
\hline
\end{tabular}

Sumber: Analisis Penulis, 2017

\section{Indikator Kolaborasi dan Partisipasi}

Pada pengembangan smart city, kolaborasi dan partisipasi merupakan salah satu indikator terpenting dalam hal tata kelola sistem perkotaan. Salah satu konsep kolaborasi maupun kerja sama yang diterapkan pada beberapa kota di dunia adalah konsep kolaborasi triple helix yaitu kolaborasi yang saling mendukung melibatkan tiga elemen yaitu pemerintah, pelaku bisnis, dan akademisi yang diterapkan sebagai bentuk strategi pemanfaatan ilmu pengetahuan untuk membangun keunggulan kompetitif dalam ekonomi berbasis pengetahuan (Menkhoff, Evers, Chay \& Pang, 2011). Sama halnya dengan konsep triple helix, indikator kolaborasi dan partisipasi terdiri dari tiga aspek dalam penilaian tingkat kesiapannya, antara lain yaitu aspek peranan pemerintah, aspek peranan institusi/ kelembagaan/ akademis, dan aspek peranan dari pelaku bisnis (UMKM Batik Surakarta). Penilaian indikator kolaborasi dan partisipasi untuk aspek peranan pemerintah dan peranan institusi/ kelembagaan/ akademis dilakukan melalui wawancara dan telaah dokumen 
kepada Dinas Koperasi dan UMKM, Dinas Perindustrian dan Tenaga Kerja, serta Dinas Perdagangan. Selain itu juga dilakukan dengan Pihak Universitas Muhammadiyah Surakarta (UMS) untuk aspek peranan institusi/ kelembagaan/ akademis. Sedangkan untuk aspek peranan dari pelaku bisnis (UMKM) dilakukan dengan survey kuesioner dan nilai skoring.

Tabel 3. Skor dan Tingkat Kesiapan Aspek Indikator Kolaborasi dan Partisipasi

\begin{tabular}{|c|c|c|c|}
\hline ASPEK & $\begin{array}{l}\text { KETERANGAN/ } \\
\text { SKOR }\end{array}$ & KATEGORI & KONDISI \\
\hline $\begin{array}{l}\text { Kolaborasi Pelaku Bisnis } \\
\text { (UMKM Batik Surakarta) }\end{array}$ & 3.072 & Kuat & $\begin{array}{l}\text { 53\% Pelaku UMKM Batik Surakarta telah } \\
\text { mengikuti program-program kerjasama yang } \\
\text { diselenggarakan oleh pemerintah, swasta, } \\
\text { maupun universitas (civitas akademis). }\end{array}$ \\
\hline $\begin{array}{l}\text { Peran Kelembagaan } \\
\text { Sektor Pemerintah }\end{array}$ & $\begin{array}{l}\text { (Telaah Dokumen } \\
\text { dan Studi Best } \\
\text { Practice) }\end{array}$ & Kuat & $\begin{array}{l}\text { Telah terdapat berbagai program dan kegiatan } \\
\text { yang diselenggarakan pemerintah Kota Surakarta } \\
\text { untuk mendorong pengembangan UMKM Batik } \\
\text { baik berupa pelatihan maupun penyediaan } \\
\text { peralatan. }\end{array}$ \\
\hline $\begin{array}{l}\text { Peran } \\
\text { Akademis }\end{array}$ & $\begin{array}{l}\text { (Telaah Dokumen } \\
\text { dan Studi Best } \\
\text { Practice) }\end{array}$ & Kuat & $\begin{array}{l}\text { Terdapat beberapa universitas yang terlibat } \\
\text { dalam kegiatan pengembangan kampung batik } \\
\text { Surakarta, yaitu UMS, UNS, dan ATW yang } \\
\text { masing-masing memiliki fokus yang berbeda. }\end{array}$ \\
\hline TOTAL & 3.072 & SIAP I & ERSYARAT \\
\hline
\end{tabular}

Sumber: Analisis Penulis, 2017

\section{Indikator Entrepreneurship}

Tingkat kesiapan dimensi ekonomi cerdas dari indikator entrepreneurship dinilai dari dua aspek yaitu kemauan untuk berubah dan tingkat pertumbuhan UMKM Batik Surakarta. Organisasi induk sektor telekomunikasi internasional, ITU-T menjelaskan bahwa kota yang mengembangkan smart economy harus memiliki kemampuan untuk menyediakan pekerjaan dan memiliki pertumbuhan ekonomi serta finansial yang baik melalui penciptaan iklim usaha yang kondusif dalam kota atau juga dengan pengembangan pola kerja usaha, agar kota mampu mendorong lahirnya pengusaha-pengusaha baru. Berdasarkan hasil penelitian yang didapatkan melalui kuesioner, skor untuk indikator entrepreneurship adalah 1.364 dan berada pada kategori siap bersyarat dalam range 1.026-1.833. Siap bersyarat artinya bahwa indikator entrepreneurship pada dasarnya telah siap untuk mendukung sistem ekonomi cerdas namun masih diperlukan beberapa syarat pengembangan untuk benar-benar dapat mendukung terciptanya smart economy. Karakteristik tingkat kekuatan masing-masing aspek dapat dilihat pada tabel 4 berikut:

Tabel 4. Skor dan Tingkat Kesiapan Aspek Indikator Entrepreneurship

\begin{tabular}{|c|c|c|c|}
\hline ASPEK & $\begin{array}{l}\text { KETERANGAN/ } \\
\text { SKOR }\end{array}$ & KATEGORI & KONDISI \\
\hline $\begin{array}{l}\text { Kemauan } \\
\text { Berubah }\end{array}$ & 1.364 & Kuat & $\begin{array}{l}53 \% \text { UMKM Batik Surakarta memiliki } \\
\text { keterbukaan untuk mengadopsi desain- } \\
\text { desain baru untuk produksi selanjutnya. }\end{array}$ \\
\hline $\begin{array}{l}\text { Tingkat } \\
\text { Pertumbuhan Pelaku } \\
\text { UMKM Batik } \\
\quad \text { TOTAL }\end{array}$ & $\begin{array}{l}\text { (Telaah Dokumen dan } \\
\text { Komparasi } \quad \text { Best } \\
\text { Practice) } \\
\quad 1.364\end{array}$ & $\begin{array}{l}\text { Kuat } \\
\text { SIAP B }\end{array}$ & $\begin{array}{l}\text { Tingkat pertumbuhan UMKM Batik } \\
\text { Surakarta selama lima tahun terakhir } \\
\text { rata-rata sebesar } 23 \% \text {. } \\
\text { RSYARAT }\end{array}$ \\
\hline
\end{tabular}

Sumber: Analisis Penulis, 2017 


\title{
Indikator Produktivitas
}

Penilaian terhadap indikator produktivitas diturunkan dari beberapa aspek penilaian yang di mana masing-masing aspek penilaian memiliki variabel-variabel untuk melihat dan mengukur tingkat kematangannya. Aspek-aspek pada indikator produktivitas antara lain meliputi modal tenaga kerja, modal finansial, sistem manajemen adminstrasi usaha, dan kualitas produk. Sedangkan untuk total jumlah total variabel yang digunakan adalah 12 (dua belas) variabel. Berdasarkan hasil kegiatan lapangan dengan menggunakan 55 sampel UMKM Batik Surakarta, total nilai skoring untuk indikator produktivitas adalah 4.043 dan memiliki level kesiapan siap bersyarat karena nilai skornya berada pada range interval 3.081-5.500. Siap bersyarat artinya bahwa indikator produktivitas pada dasarnya telah siap untuk mendukung sistem ekonomi cerdas namun masih diperlukan beberapa syarat pengembangan untuk benar-benar dapat mendukung terwujudnya prinsip-prinsip dari dimensi ekonomi cerdas. Syarat-syarat pengembangan tersebut dapat dilihat berdasarkan tingkat kekuatan aspek yang ditunjukkan pada tabel 5 berikut:

Tabel 5. Skor dan Tingkat Kesiapan Aspek Indikator Produktivitas

\begin{tabular}{lcccc}
\hline & ASPEK & SKOR & \multicolumn{1}{c}{ KONDISI } \\
\hline Modal & Tenaga & 1.659 & Kuat & $\begin{array}{l}47 \% \text { UMKM Batik Surakarta memiliki jumlah tenaga } \\
\text { Kerja }\end{array}$ \\
& & & $\begin{array}{l}\text { kerja 5-8 orang yang didominasi pekerja berusia 25-35 } \\
\text { tahun dan jumlah produksi rata-rata sekitar 20-50 buah/ } \\
\text { hari. }\end{array}$
\end{tabular}

Modal Finansial $\quad 890 \quad$ Kuat

\begin{abstract}
Hanya sebagian kecil (35\%) UMKM Batik Surakarta yang mendapatkan modal dari akses perbankan dan 44\% UMKM Batik Surakarta merasa adanya peningkatan pendapatan yang sangat meningkat dari kegiatan UMKM.
\end{abstract}

Sistem Manajemen

$818 \quad$ Lemah

58\% UMKM telah memiliki sistem pembukuan usaha yang dipisahkan dengan keuangan keluarga namun belum begitu terstruktur yang berdampak pada intensitas perencanaan dan evaluasi usaha.

Administrasi Usaha

Sumber: Analisis Penulis, 2017

SIAP BERSYARAT

\section{Indikator Daya Saing}

Penilaian terhadap indikator daya saing diturunkan melalui beberapa aspek penilaian yang masing-masing aspek penilaian memiliki variabel-variabel penilaian untuk melihat bagaimana tingkat kesiapan/ kematangannya. Adapun aspek-aspek yang terdapat pada indikator daya saing antara lain; lingkungan usaha, infrastruktur pendukung, perekonomian daerah, dan tenaga kerja/ sumberdaya manusia. Untuk aspek perekonomian daerah dinilai melalui komparasi data-data eksisting mengenai UMKM Batik Surakarta yang didapatkan dari dinas-dinas terkait dengan data-data sejenis pada kota-kota yang menerapkan sistem ekonomi cerdas (best practice), selain itu juga kondisi eksisting akan dijelaskan dan dikomparasikan dengan literatur-literatur terkait. Sedangkan untuk aspek-aspek lainnya dinilai berdasarkan nilai skoring dari variabel-variabel yang ada pada setiap aspek pembentuk indikator daya saing. Jumlah total variabel yang digunakan untuk menilai 
indikator daya saing adalah 10 (sepuluh) variabel. Berdasarkan hasil nilai skoring kepada 55 sampel UMKM Batik Surakarta, didapatkan jumlah skor sebesar 3.550 dan memiliki level kesiapan siap bersyarat karena nilai skoringnya berada pada skor range interval 1.283-2.291. Siap bersayarat artinya bahwa UMKM Batik Surakarta sudah dapat dikatakan memiliki daya saing untuk produk yang dikembangkan dan aspek-aspek pembentuknya telah memiliki keunggulan-keunggulan yang diciptakan melalui sistem ekonomi cerdas namun masih diperlukannya beberapa syarat perbaikan untuk benar-benar mendukung terciptanya ekonomi cerdas. Syarat-syarat perbaikan tersebut dapat dilihat sebagaimana kategori masing-masing aspek yang dijabarkan pada Tabel 6 berikut.

Tabel 6. Skor dan Tingkat Kesiapan Aspek Indikator Daya Saing



Sumber: Analisis Penulis, 2017

\section{KESIMPULAN}

Temuan hasil kesimpulan penelitian ini menunjukkan bahwa indikator-indikator penilaian yang terdiri dari innovative spirit, kolaborasi dan partisipasi, entrepreneurship, produktivitas, dan daya saing, masing-masing indikator memiliki level kesiapan siap bersyarat dengan indeks performa berada pada range 33\% - 66\%, oleh karena itu bila setiap indikator tersebut saling diakumulasikan maka akan dapat dilihat bagaimana tingkat kesiapan UMKM Batik Surakarta terhadap dimensi ekonomi cerdas. Hasilnya adalah siap bersyarat. Siap bersyarat tentunya belum merupakan level kesiapan maksimum karena untuk dapat benar-benar dianggap dapat mendorong terwujudnya dimensi ekonomi cerdas, masih diperlukan upaya-upaya perbaikan, pengembangan, peningkatan, maupun pengadaan pada beberapa aspek dari setiap indikator kesiapan. Melalui perhitungan dan analisis kondisi yang diturunkan dari setiap aspek, hal-hal yang paling perlu untuk diperhatikan untuk dilakukan peningkatan performa yaitu (1) aspek sistem pengambilan keputusan dari indikator innovative spirit. Sebanyak 57\% UMKM Batik Surakarta masih pasif dalam hal perencanaan, evaluasi dan perlibatan pekerjanya dalam pengambilan keputusan untuk menciptakan inovasi usaha; (2) aspek kerjasama dari indikator innovative spirit. Sekitar $78 \%$ UMKM Batik Surakarta belum melakukan kegiatan kerjasama dan kolaborasi yang bersifat sustainable antar unit internal maupun eksternal sebagai upaya untuk menciptakan inovasi 
dalam kegiatan usaha; (3) aspek sistem manajemen administrasi usaha dari indikator produktivitas. Secara kasar, terdapat 58\% UMKM telah memiliki sistem pembukuan usaha yang dipisahkan dengan keuangan keluarga namun belum begitu terstruktur yang berdampak pada intensitas perencanaan dan evaluasi usaha.

Berdasarkan hasil temuan tersebut, ketiga aspek memiliki performa yang masih lemah untuk dapat mendorong terwujudnya dimensi ekonomi cerdas. Kondisi tersebut tentunya memberikan pandangan baru bagi stakeholder terkait terhadap perlunya upaya peningkatan performa usaha ataupun melalui kegiatan pendampingan bagi pelaku UMKM Batik agar terwujud pondasi-pondasi pengembangan dimensi ekonomi cerdas yang kuat. Pendekatan yang dilakukan dapat dengan melihat aspek-aspek yang memiliki karakter dan kapasitas yang sangat kuat dalam mendorong penerapan dimensi ekonomi cerdas. Aspek tersebut meliputi aspek technology awareness dan aspek lingkungan usaha.

\section{DAFTAR PUSTAKA}

Bank Indonesia; Lembaga Pengembangan Perbankan Indonesia. (2015). Profil Bisnis Usaha Mikro, Kecil, dan Menengah (UMKM). Jakarta: Bank Indonesia.

BPS Kota Surakarta. 2016. Kota Surakarta dalam Angka Tahun 2016.

Borsekova, K., Vanova, A., \& Vitalisova, K. (2016). The Power of Communities in Smart Urban Development. Procedia - Social and Behavioral Sciences, 223, 51-57. https://doi.org/10.1016/j.sbspro.2016.05.289

Cho, D.-S., Moon, H.-C., \& Kim, M.-Y. (2008). Characterizing international competitiveness in international business research: A MASI approach to national competitiveness. Research in International Business and Finance, 175-192.

Creswell, J. W. (2009). Research Design: Qualitative, Quantitative, and Mixed Methods Approaches. Sage Publication.

Dinas Perdagangan. (2017). Data Realisasi Ekspor Kota Surakarta tahun 2012-2016. Kota Surakarta: Dinas Perdagangan Kota Surakarta.

Etzkowitz, H., \& deMello. (2004). The Rise of a Triple Helix Culture: Innovation in Brazilian economic and social development. International Journal of Technology Management \& Sustainable Development, 159-171.

Evers, H.-D. (2008). Knowledge hubs and knowledge clusters: Designing a knowledge architecture for development. Munich Personal RePEc Archive, 1-21.

FPKBL. (2017, Oktober 1). Festival Laweyan. Surakarta, Jawa Tengah, Indonesia.

Giffinger, P. M. (2007). European smart cities - New scientific ranking instrument for European middle-sized cities. Munich Expo Real. Munich: Technical University of Vienna.

Govada, S., Spruijt, W., \& Rodgers, T. (2017). China-Hong Kong Hksar. In T. V. Kumar, Smart Economy in Smart Cities (pp. 171-245). New Delhi: Springer.

Hansen, M. T., \& Birkinshaw, J. (2009). The Innovation Value Chain. Harvard Business Review, (2007), 1-7.

Huda, M., \& Santoso, E. B. (2014). Pengembangan Daya Saing Daerah. JURNAL TEKNIK POMITS, 2301-9271.

ISO/ IEC JTC 1. (2015). Smart Cities. Switzerland: ISO.

Joshi, S., Saxena, S., Godbole, T., \& Shreya. (2016). Developing Smart Cities: An Integrated Framework. Procedia Computer Science, 93(September), 902-909. https://doi.org/10.1016/j.procs.2016.07.258

Kumar, T. M. V., \& Dahiya, B. (2017). Smart Economy in Smart Cities. Smart Economy in Smart Cities. https://doi.org/10.1007/978-981-10-1610-3

Martini, L., Tjakraatmadja, J. H., Anggoro, Y., Pritasari, A., \& Hutapea, L. (2012). Triple Helix Collaboration to Develop Economic Corridors as Knowledge Hub in Indonesia. Procedia - Social and Behavioral Sciences, 52, 130-139. https://doi.org/10.1016/j.sbspro.2012.09.449

Menkhoff, T., Evers, H. D., Wah, C. Y., \& Fong, P. E. (2011). Beyond The Knowledge Trap: Developing Asia's Knowledge-Based Economies. Singapore: World Scientific Publishing Co, Pte.Ltd.

Pontoh, Nia K \& Kustiawan, Iwan. (2009). Pengantar Perencanaan Perkotaan. Bandung: Penerbit ITB.

Pusponegoro, M., Saim, M., \& Muttaqin, H. (2007). Kauman Religi, Tradisi, dan Seni. Surakarta: Paguyuban Kampung Batik Kauman.

Richter, C., Kraus, S., \& Syrjä, P. (2015). The Smart City as an opportunity for entrepreneurship. International Journal of Entrepreneurial Venturing, 7(3), 211-226. https://doi.org/10.1504/IJEV.2015.071481 
Rogers, E. M. (1993). Diffusion of Innovations. New York: THE FREE PRESS-A Division of Simon \& Schuster Inc.

Sharma, S. (2017, Desember 11-15). ICT Trends, Innovation and Entrepreneurship. Peradeniya, Sri Lanka.

Sugiyono. (2008). Metode Penelitian Kunatitatif Kualitatif dan R\&D. Bandung: Alfabeta.

Sugiyono. (2014). Metode Penelitian Kuantitatif, Kualitatif, dan Kombinasi (Mixed Methods). Bandung : Alfabeta Sulistyorini, U. T. (2017). Peningkatan Kinerja Produk Melalui Pemberdayaan Inovasi: Studi Kasus pada UKM Batik Tulis Ekspor Surakarta. Politeknik Negeri Semarang, 167-187.

Supangkat, S. H. (2015). Pengenalan dan pengembangan Smart City. Bandung: e-Indonesia Initiatives.

Von Hippel, E. (2005). Democratizing innovation. Journal für Betriebswirtschaft (Vol. 55). Cambridge. https://doi.org/10.1111/j.1540-5885.2006.00192_2.x

Weismeier-Sammer, D. (2011). Entrepreneurial behavior in family firms: A replication study. Journal of Family Business Strategy, 128-138. 